\title{
ПОЛИТИЧЕСКАЯ КАРИКАТУРА \\ КАК ЖАНР ПОЛИКОДОВОГО ТЕКСТА В СТРУКТУРЕ ПРОПАГАНДИСТСКОГО ДИСКУРСА
}

\section{Вагизова В.В.}

Статья посвящена пропаганде как инструменту воздействия на общественное сознание. Приводятся данные анализа поликодовых текстов в структуре пропагандистского дискурса на материале политических карикатур на Северную Корею в американских СМИ. Проблема рассматривается с точки зрения дискурсивного анализа.

Целью исследования является выявление роли и взаимосвязи вербального и невербального компонентов поликодовых текстов политической карикатуры и их манипулятивного потенцииала в дискурсе американской пропаганды, направленной на демонизацию Северной Кореи и ее лидера.

Материалы и методы. Материалом для исследования послужсил корпус политических карикатур на лидера Северной Кореи из электронного издания новостного американского журнала «U.S. News \& World Report». В ходе работы над статьей были использовань методы мультимодального анализа, контекстуального анализа, коммуникативного анализа, элементы критического дискурс-анализа и метод сплошной выборки.

Результаты. Результаты анализа теоретической и практической базы исследования выявили взаимосвязь вербального и невербального компонентов поликодовых текстов. Рассмотренные политические карикатуры обладают большими манипуляционными возможностями и содержат признаки информаџионной войны.

Область применения результатов. Выявленные в результате исследования тактики и языковые средства речевого воздействия могут быть использованы в дальнейшем анализе поликодовых тек- 
стов политической карикатуры и в лингвистической экспертизе материалов пропагандистского характера.

Ключевые слова: информационная война; пропаганда; пропагандистский дискурс; поликодовый текст; карикатура; Ким Чен Ын; Северная Корея

\section{POLITICAL CARTOON AS A GENRE OF POLYCODE TEXT WITHIN THE PROPAGANDA DISCOURSE}

\section{Vagizova $\boldsymbol{V} . \boldsymbol{V}$.}

The article is devoted to the propaganda studying as an instrument for influencing public consciousness. It also provides data on polycode text analysis within the propaganda discourse based on the political cartoons of North Korea in the American mass media. The problem is considered from the point of view of discourse analysis.

Purpose. The research is devoted to identifying the role and connection between verbal and non-verbal components of polycode texts in political cartoons and their manipulative capacity within the American propaganda discourse aimed at demonizing both North Korea and its leader.

Research materials and methods. The political cartoons of North Korean leader were taken and studied from the American internet news edition U.S. News \& World Report. For the purposes of the study the following methods were used: methods of multimodal analysis, contextual analysis, communicative analysis, elements of critical discourse analysis and continuous sampling method.

Results. The results of the theoretical analysis and experimental work identified the relationship between verbal and non-verbal components of polycode texts. The political cartoons under study have great manipulative capabilities and contain the signs of information warfare.

Practical implications. The tactics and linguistic means of persuasion revealed by the research can be used in further analysis of polycode cartoon texts as well as in linguistic examination of propaganda materials. 
Keywords: information warfare; propaganda; propaganda discourse; polycode text; political cartoon; Kim Jong-un; North Korea

\section{Введение}

В 21 в., называемом веком информационных технологий, информация становится одним из основных ресурсов, потребляемых современным человеком. От ее содержания, актуальности, канала передачи и целевой аудитории зависят решения военно-политических, экономических и иных задач в интересах как отдельной личности, так и государства в целом.

При отстаивании государствами своих геополитических интересов наметилась тенденция к переходу от «горячих» (силовых) методов воздействия к «холодным». Важное значение среди них имеют информационные методы, способные дискредитировать потенциального противника в лице государства, правительства, политического лидера. Одним из важнейших информационных каналов являются массмедиа. Их массовая аудитория - это удобный объект манипулирования, осуществляемого, в частности, в рамках пропаганды.

Становится очевидным, что проникновение приемов пропаганды как способа манипулирования человеческим сознанием из военно-политической области в другие сферы деятельности общества (PR-технологи, политическая агитация, политические массмедийные технологии и др.) заставило ученых обратить особое внимание на изучение данного вопроса.

Целью исследования является выявление взаимосвязи и роли вербального и невербального компонентов поликодовых текстов политической карикатуры и их манипулятивного потенциала в дискурсе американской пропаганды, направленной на демонизацию Северной Кореи и ее лидера.

Актуальность выбора темы обусловлена неполнотой теоретической и практической базы для лингвистического исследования методов, речевых тактик и стратегий, а также языковых маркеров манипулятивного воздействия; необходимостью дальнейшего рас- 
ширения понятийного аппарата лингвистики информационно-психологической войны в целях усовершенствования политики России в области информационного противоборства.

Новизна работы обусловлена ее актуальностью, направление исследования вписывается в рамки достаточно нового научного направления «Лингвистика информационно-психологической войны», активно разрабатываемого учеными-лингвистами Института филологии и языковой коммуникации Сибирского федерального университета (Красноярск).

\section{Дискурс пропаганды в контексте информационной войны}

В нашей работе за основу взято определение информационной войны, предложенное лингвистом А.П. Сковородниковым. Он рассматривает информационную войну «как противоборство сторон, возникающее из-за конфликта интересов и/или идеологий и осуществляемое путем целенаправленного информационного воздействия друг на друга с использованием специальных технологий для получения определенного преимущества в материальной и/или идеологической сфере и защиты собственной безопасности» [14, с. 12].

Согласно ряду исследователей, информационная война и война с применением силовых методов часто ведутся параллельно. Первый вид противоборства может спровоцировать или оправдать второй [12, с. 194].

Главная цель информационной войны заключается в изменении массового сознания в выгодном для оппонента направлении. Должный эффект достигается путем использования различных приемов. Пропаганда является наиболее распространенным способом манипуляции общественным сознанием [10, с.49].

Термин «пропаганда» (от лат. propaganda - 'подлежащее распространению’) произошел от названия Конгрегации Пропаганды Веры (Sacra Congregatio de Propaganda Fide), основанной в 1622 г. римским папой Урбаном VII. Папская пропаганда была учреждена в целях продвижения идей католической церкви среди населения и в рамках идеологической борьбы с протестантами. Изначально 
слово имело нейтральное значение, однако со временем приобрело негативную коннотацию - «массовое внушение или влияние через манипуляцию символов и психологию индивидуума» [15; 22, p. 2].

Известный американский теоретик пропаганды Г. Лассуэлл отмечал, что пропаганда призвана изменять мировоззрение людей. Как способ массового убеждения, она насаждает политические взгляды элит. Пропаганда является более «экономным» видом оружия, чем традиционные виды. Пропаганда - это «инструмент тотальной политики вместе с дипломатией, экономическими мероприятиями и вооружёнными силами. Её цель заключается в экономии материальных затрат на мировое господство» [15].

Объектом воздействия пропаганды является мировоззрение широких социальных групп: «Пропаганда представляет собой воздействие на сознание (подсознание), политические и ценностные ориентации объектов (групп объектов) посредством распространения воззрений, идей, учений с целью формирования мировоззрения, соответствующего интересам воздействующей стороны» [15; 23, р. 629].

Нередко пропаганду ассоциируют с коммуникативной технологией, представляющей собой «наиболее быстрый (по причине массовости) и наименее затратный (по причине отсутствия «обратной связи») способ внедрения идей в сознание адресата пропагандистской коммуникации» [18, с. 3].

Пропаганда является наиболее эффективной, когда остается незаметной для адресата. В данном случае характер источника информации (официальное или неофициальное новостное агентство) не имеет значения. Читатель подвергается влиянию пропагандистского контента без его ведома, и в результате некоторые его суждения могут быть изменены [20, p. 1849].

Определенные институты или организации как источники пропаганды являются заказчиками для исполнителей и непосредственно определяют содержание пропаганды [5, с. 227; 11, с. 38].

К конститутивным чертам пропаганды относят: наличие коммуникатора как выразителя мнения большой по численности социальной группы; амбивалентность сообщения по отношению к его 
правдивости, истинности; попытка вызвать эмоции адресата коммуникации; массовый характер; монологичность текста, отсутствие обратной связи [18, с. 2].

Чтобы сообщение считалось пропагандой, оно должно соответствовать трем критериям:

- наличие осознанной попытки манипулировать мнением других людей;

- в сообщении представлена лишь одна из сторон конфликта; таким образом, создается впечатление, что оно является безоговорочной истиной;

- намерение, которое содержится в сообщении, тщательно замаскировано, чтобы слушатели не воспринимали его как пропаганду. Для достижения необходимого эффекта пропагандист должен обдумать объект пропаганды, правдоподобие информации, средства передачи и цель сообщения. Эффективность пропагандистского сообщения сложно оценить, однако его воздействие на аудиторию очевидно [13, с. 56].

В нашей работе в качестве рабочего определения используется понимание пропаганды Ю.В. Безбородовой и Л.В. Коростелевой: «политически мотивированное информационно-психологическое воздействие на эмоционально-волевую сферу массового сознания, с помощью которого внедряются политические идеи, взгляды, установки и формируется политическое поведение, которое не допускает альтернативной точки зрения» [3, с. 160].

Среди других форм речевого воздействия пропаганду выделяет ряд особенностей: целенаправленность, поэтапность, системность, наличие вербальной и материальной составляющей. Целенаправленность заключается в том, что для достижения пропагандистских целей распространяется не любая, а конкретная информация. Поэтапность заключается в разделении пропаганды на несколько этапов: получение информации, обработка, определение средств распространения и непосредственно распространение конкретной информации в массовом сознании. Системность проявляется на разных уровнях, в разных направлениях. Например, при выборе 
средств получения, обработки и распространения определенной информации; при систематизации действий субъектов, в системности воздействия на массовое сознание. Наличие вербальной и материальной составляющей позволяют оказывать воздействие на главные сферы сознания человека, использовать результаты действий человека [16, с. 88].

В целях повышения эффективности применяются различные приемы и методы пропаганды. Например, к таким приемам относится подбор фактов для усиления или ослабления высказывания; введение сравнения; дозировка позитива и негатива для того, чтобы похвала выглядела правдоподобнее.

В дополнение к вышеперечисленным приемам выделяют такие приемы воздействия, как использование демотиваторов, карикатур, фотографий для усиления эмоционального воздействия на общественное создание [16, с. 88].

Важность данного приема, отмечаемая исследователями, позволяет нам обратиться к исследованию и анализу пропаганды именно в рамках поликодовых текстов.

\section{Политическая карикатура как жанр поликодового текста в структуре пропагандистского дискурса}

Как известно, пропаганда может реализовываться как в вербальной форме, так и в невербальной форме (визуальные образы, музыка, фильмы). Некоторые авторы отмечают, что использование невербальных символов вообще является непременной отличительной чертой пропаганды [2, с. 54].

При этом необходимо отметить, что вербальные средства оказывают влияние на сознание человека, в то время как невербальные (паралингвистические) средства воздействуют на область подсознания [7, с. 26].

Тексты, содержащие в своем составе элементы различных семиотических систем, имеют различные наименования в современном научном языке: поликодовые, креолизованные, изовербальные, семиотически осложненные, полимодальные и др. Чаще других вариан- 
тов используются термины «креолизованный текст» и «поликодовый текст». Эти понятия являются довольно близкими, но не совпадают друг с другом. Креолизованный текст представляет собой «... особый лингвовизуальный феномен, текст, в котором вербальный и изобразительный компоненты образуют одно визуальное, структурное, смысловое и функциональное целое, обеспечивающее его комплексное практическое воздействие на адресата» [1, с. 63].

Как отмечает А.Г. Сонин, поликодовый текст - это специфическое речевое произведение, образуемое взаимодействием изобразительной и вербальной составляющих в едином графическом и смысловом пространстве. Под графическим структурированием текста понимается использование для выражения актуального личностного смысла совокупности разнородных элементов: цвета, разных отдельных элементов рисунка, пространственных планов, углов зрения, графем, которым приписывается особое содержание, знаков препинания и др. [17, с. 119].

В настоящем исследовании нами сделан выбор в пользу термина «поликодовый текст», потому как он наиболее точно и полно выражает суть изучаемого феномена. Изначально понятие «поликодового текста» было предложено в 1974 г. Г.В. Ейгером и В.Л. Юхтом. По их мнению, «к поликодовым текстам в широком семиотическом смысле должны быть отнесены случаи сочетания естественного языкового кода с кодом какой-либо иной семиотической системы (изображение, музыка и т. п.)» [9, с. 107].

Разновидностью поликодового текста, совмещающего в себе вербальные и невербальные компоненты, является политическая карикатура. Она может как отражать общественное мнение, так и изменять убеждения адресатов относительно конкретных социально-политических вопросов; содержать в себе определенную точку зрения автора на политиков и/или положение дел [24, p. 118; 21, p. 11].

В репрезентации образа врага нередко используется смеховая культура, яркими примерами которой являются карикатура или анекдот. Именно они получили широкое распространение в массмедийной коммуникации. 
В центре внимания нашего исследования представлена именно политическая карикатура как разновидность поликодового текста, играющая большую роль в формировании образа врага в сознании аудитории и обладающая большим манипулятивным потенциалом.

Согласно мнению многих современных исследователей, наиболее важным механизмом формирования любой группы в обществе является конструирование образа врага. Именно «по отношению к образу внешнего врага “Они-группа” сплачивается и становится “Мы-группой”». Адекватный образ внешнего врага повышает как управляемость социальной группой, так и внутреннюю солидарность. Необходимо отметить, что активно формируемый образ врага превращается в пропагандистский миф или мощное орудие манипуляции. Феномен сплочения перед лицом угрозы является достаточно эффективным средством в любой социальной группе [19, с. 123].

Согласно М.Б. Ворошиловой, при анализе креолизованных (поликодовых) текстов выделяют три сформировавшихся подхода: «1) семиотическое направление, в том числе работы по концептуальной метафорике; 2) структурно-риторическое направление, посвященное вопросам взаимодействия языковой и иконической составляющей креолизованного (поликодового) текста; 3) коммуникативное направление, в центре внимания исследователей проблема коммуникативных стратегии и тактик» [6, с. 74].

В нашем исследовании политические карикатуры на лидера Северной Кореи в американских СМИ проанализированы с учетом структурно-риторического и коммуникативного подходов, которые фокусируются на вопросах взаимодействия вербального (языкового) и невербального (иконического) компонентов поликодового текста.

\section{Материалы и методы}

В качестве материала для нашего исследования послужил исследовательский корпус карикатур в количестве 50 единиц, объектом высмеивания в которых является политический курс Северной Кореи, ее лидер или идеология. Все карикатуры были отобраны методом сплошной выборки из электронного издания новостно- 
го американского журнала «U.S. News \& World Report». Выбор журнала обусловлен его высоким рейтингом в кругах читателей и повышенным вниманием к вопросам международной политики и экономики, в рамках которых особую роль занимают американо-северокорейские отношения.

В качестве методов использовались методы мультимодального анализа политического текста, метод контекстуального анализа, элементы критического дискурс-анализа и коммуникативного анализа.

\section{Анализ и результаты}

На всех карикатурах (например, рис. 1-3) в целях дискредитации власти лидер Северной Кореи представлен в роли мишени информационной войны (информационно-психологической войны), ведущейся правительством США посредством СМИ. В мишени информационно-психологической войны (далее - ИПВ) основной удар приходится на ядро (или болевую точку). Согласно А.П. Сковородникову, «под мишенью мы понимаем ту сторону действительности, так или иначе связанную с объектом, которая подвергается дискредитации для того, чтобы воздействовать определенным образом на объект» [14, с. 64].

Проведенный анализ карикатур на северокорейского лидера показал, что распространенными тактиками являются тактика «навешивания» ярлыков, тактика уничижительно-иронического преуменьшения каких-либо достоинств мишени (силы, значимости, качества, масштабности и т.д.) и тактика преувеличения ее недостатков.

Что касается языковых маркеров ИПВ, которые участвуют в реализации определенных тактик, на первом месте по частоте употребления находятся лексико-фразеологические средства языка:

1) слова и фразеологизмы с отрицательно-оценочной коннотацией, характеризующие мишень ИПВ (идеологию, партию, процесс, личность); слова, обозначающие негативные явления, например, blow up - взрывать (рис. 2), и служащие для реализации тактики навешивания ярлыков; 
2) стилистические тропы и фигуры, под которыми понимаются прагматически мотивированные отклонения от речевой нейтральной или языковой нормы, усиливающие экспрессивность высказывания:

- трансформация фразеологизма или прецедентного текста: Make America Great Again - Make America disappear (рис. 1);

- метафора, выражающая оценку: The world's biggest baby... (рис. 2).

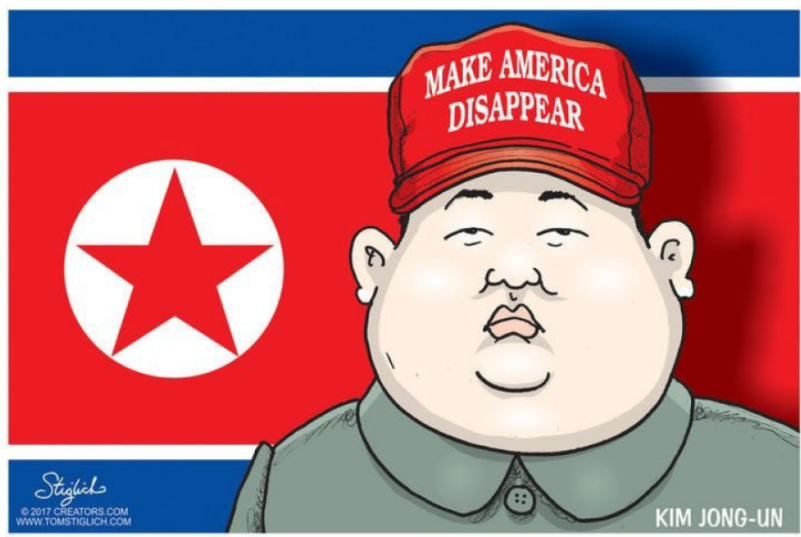

Pис. 1. Make America disappear

На карикатуре (рис. 1) представлен визуальный образ лидера Северной Кореи Ким Чен Ына в гиперболизированном виде.

Иконический компонент поликодового текста включает изображение северокорейского лидера на фоне государственного флага КНДР.

Изображение лидера на фоне государственного флага свидетельствует об олицетворении его с символом власти, государством, проводимой политикой Чучхе (северокорейская националистическая государственная идеология). Красный цвет и звезда на северокорейском флаге символизируют идеологию государства. Здесь мы прослеживаем некую аллегорию: идеология и государственность - флаг - лидер государства. Сам Ким Чен Ын изображен в 
нетипичном для тоталитарного лидера образе. С одной стороны он одет в привычный протокольный костюм, в котором часто появляется на правительственных заседаниях, с другой стороны - на голове лидера присутствует красная кепка с надписью «Make America disappear» («Заставим Америку исчезнуть с лица земли»). Кепка лидера КНДР является аналогом кепки Дональда Трампа с надписью «Make America Great Again» («Вернем Америке былое величие»)», которую он надевал преимущественно во время президентской кампании 2016 г. Данный лозунг использовался американскими президентами и раньше, например Рональдом Рейганом и Биллом Клинтоном. Таким образом, надпись на кепке Ким Чен Ына «Make America disappear» является своего рода лозунгом, угрозой безопасности США и несогласием с проводимым ей политическим курсом.

Как мы отмечали ранее, в «мишени пропагандистского воздействия может быть выделено ядро (или болевая точка), на которое направлен основной удар субъекта информационно-психологической войны» [14, с. 23]. В данном случае (рис. 1) мишенью ИПВ и объектом демонизации является лидер КНДР.

Выделим внешность лидера в качестве болевой точки (ядра), на которой в карикатурах авторы акцентируют особое внимание. На рис. 1 визуально подчеркивается и преувеличивается физическая особенность лидера (излишняя полнота), которая становится потенциальным объектом насмешек со стороны субъектов ИПВ. Таким образом, мы можем констатировать факт применения тактики преувеличения недостатков.

Помимо наглядности, иконический компонент на рис. 1 актуализирует следующие ассоциативные связи: символические, цветовые, ассоциаций по форме, интегрированные с резко отрицательной эмоцией. В данном случае отрицательные эмоции служат основой в создании образа врага. Вербальный компонент поликодового текста включает надпись на кепке лидера КНДР «Make America disappear» («Заставим Америку исчезнуть с лица земли»)

В качестве языкового маркера ИПВ в данной карикатуре (рис. 1) отметим использование трансформации прецедентного выска- 
зывания: Make America Great Again (прецедентное высказывание) Make America disappear (см. рис. 1).

Таким образом, проанализировав иконический и вербальный компоненты карикатуры (рис. 1), можно судить о наличии признаков манипулятивного воздействия акторов ИПВ на сознание объектов ИПВ.

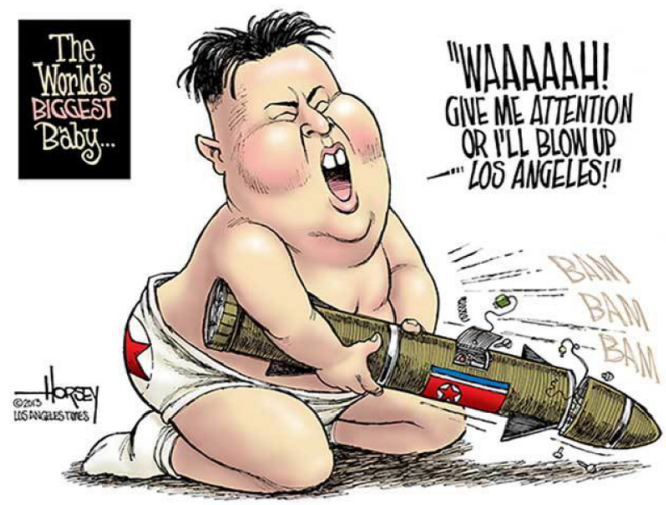

Pис. 2. The World's Biggest Baby

Иконический компонент. На рис. 2 лидер Северной Кореи изображен в виде капризного ребенка, играющего с межконтинентальной баллистической ракетой.

Изображение лидера в виде капризного ребенка может свидетельствовать о применении актором ИПВ тактики уничижительно-иронического преуменьшения достоинств мишени (значимости, масштабности, качества, силы) или тактики «навешивания» ярлыков. «Капризный маленький ребенок» В данном случае может быть расценен как ярлык.

В иконическом компоненте карикатуры также представлена ракета как символ политики государства и ядерной программы КНДР.

Анализ вербального компонента (рис. 2) демонстрирует ряд специфических черт.

Употребление превосходной степени сравнения слова big (the biggest) придает дополнительную экспрессию образу лидера КНДР, представляя его как опасного непредсказуемого политика. Надпись 
«The world's biggest baby...» является метафорическим выражением образа северокорейского лидера. Также в надписи «The world's biggest baby...» (Самый большой ребенок в мире) присутствует и графическое выделение красным цветом слова biggest, что свидетельствует о негативной эмоциональной оценке.

«WAAAAAH! Give me attention or I'll blow up Los Angeles!» - BAAAAAX! Обратите на меня внимание или я взорву Лос-Анжелес!

В данном контексте междометие WAAAAAH выражает досаду. Досада лидера КНДР в данном случае вызвана отсутствием уважения к нему как к политическому лидеру на мировой арене. К тому же для дополнительной экспрессии в междометии WAAAAAH! присутствует как графическое выделение буквы А (многократный повтор), так и пунктуационное выделение в предложении знаком «!». Императив «Give me attention or I'll blow up Los Angeles!» свидетельствует о желании северокорейского лидера диктовать миру свои политические условия. Что касается лексических средств выражения, в предложении используется глагол blow up - 'взрывать', приобретший в контексте террористических актов последнего десятилетия отрицательно-оценочную коннотацию, который характеризует мишень (лидера КНДР) как потенциального террориста.

В предложении используется звукоподражательное слово «ВАМ», которое передает звук разорвавшейся ракеты, что негативно характеризует действия лидера Северной Кореи. Для усиления эмоционального эффекта на аудиторию звукоподражательное слово повторяется несколько раз и графически выделено заглавными буквами.

Следующая карикатура (рис. 3) символизирует заигрывание северокорейского лидера с национальным символом США белоголовым орланом, который олицетворяет собой страну и ее демократию. Северокорейский лидер изображен в виде поющей пчелы, что предполагает использование тактики уничижительно-иронического преуменьшения достоинств мишени (значимости, масштабности, силы, качества). Данная тактика уничижает значимость северокорейского лидера и изображает его как назойливого насекомого, чья политика не вписывается в международные стандарты. Из вербаль- 
ных (языковых) средств используется только звукоподражательное слово «NA-NANA-NANA-NAH» - звук поющей пчелы, который является дополнением к изобразительному образу лидера Северной Кореи, но не его пояснением.

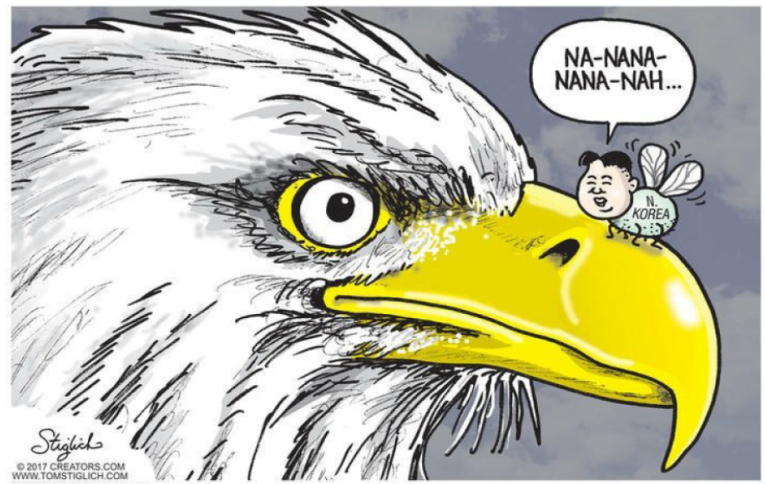

Рис. 3. The Bold Eagle and the North Korean leader

\section{Заключение}

Таким образом, проанализировав политические карикатуры на лидера Северной Кореи, мы пришли к следующим выводам:

- поликодовые тексты являются синтезом изобразительных (невербальных) и вербальных компонентов, каждый из которых выполняет свою оценочную, экспрессивную функцию;

- поликодовые тексты несут как эксплицитный, так и имплицитный смысл, для истолкования которых требуются экстралингвистические знания;

- поликодовые тексты, специфическим жанром которых является политическая карикатура, обладают большим манипуляционным потенциалом и играют существенную роль в формировании образа врага;

- пропаганда как способ манипуляции сознанием осуществляется посредством каналов СМИ и Интернета;

- как прием визуализации иконический компонент позволяет автору пропагандистского сообщения в виде карикатуры 
формировать безальтернативную точку зрения у аудитории относительно мишени ИПВ;

- визуальный компонент поликодовых текстов воздействует на сознание объектов ИПВ на лексическом, стилистическом, грамматическом, графическом уровнях.

Рассмотренные поликодовые тексты содержат признаки ИПВ, объектом воздействия которых является массовое сознание американцев, а мишенью выступает лидер Северной Кореи.

Для реализации стратегии дискредитации политического противника используются тактики, являющиеся средством манипулирования общественным сознанием: тактика уничижительно-иронического преуменьшения достоинств мишени, тактика «навешивания» ярлыков, тактика преувеличения недостатков мишени.

Поскольку исследование языкового аспекта ИПВ относительно недавно стало объектом научного интереса лингвистов, существует необходимость в продолжении подобных исследований в целях обеспечения информационной безопасности государства.

\section{Список литературы}

1. Анисимова Е.Е. Лингвистика текста и межкультурная коммуникация (на материале креолизованных текстов. М.: Академия, 2003. $107 \mathrm{c}$.

2. Баранов А.Н., Паршин П.Б. Категория пропаганды в лингвистической экспертизе текста // Теория и практика судебной экспертизы. 2017. Том 12. № 2. С. 53-65.

3. Безбородова Ю.В., Коростелева Л.В. Креолизованный текст в структуре пропагандистского дискурса // Политическая лингвистика. 2019. № 6 (78). С. 159-163.

4. Белоконева А.С. Конструирование образа внешнего врага: исследование советских СМИ и официальных документов начала холодной войны: Автореф. дис. ... канд. социол. наук. М., 2004. 24 с.

5. Войтасик Л. Использование психологии в системе пропаганды // Реклама: внушение и манипуляция. Медиа-ориентированный подход. Самара: Бахра-М, 2001. С. 208-286. 
6. Ворошилова М.Б. Креолизованный текст в политическом дискурсе // Политическая лингвистика. 2007. № 3 (23). С. 73-78.

7. Ворошилова М.Б. Политический креолизованный текст: ключи к прочтению: монография. Екатеринбург: Уральский государственный педагогический университет, 2013. 194 с.

8. Гудков Л.Д. Негативная идентичность: статьи 1997-2002 годов. М.: Новое лит. обозрение: ВЦИОМ-А, 2004. 807 с.

9. Ейгер Г.В. К построению типологии текстов // Лингвистика текста: материалы науч. конф., МГПИИЯ: в 2 ч. Ч. 1. М.: МГПИИЯ, 1974. C. 103-109.

10. Иванов С.А. Пропаганда и информационные войны //Дневник алтайской школы политических исследований. 2012. № 28. С. 49-53.

11. Каменева В.А. Манипуляция и/или пропаганда? Функциональные особенности социальной рекламы // Политическая лингвистика. 2013. № 2 (44). С.35-39.

12. Колмогорова А.В., Калинин А.А., Талдыкина Ю.А. Языковые маркеры манипуляции в поляризованном политическом дискурсе: опыт параметризации // Политическая лингвистика. 2016. № 4 (58). С. 194-199.

13. Кордуэлл М. Психология. А-Я: Словарь-справочник / пер. с англ. К.С. Ткаченко. М.: Фаир-пресс, 2000. 448 с.

14. Лингвистика информационно-психологической войны: монография. Книга I / А.А. Бернацкая, И.В. Евсеева, А.В. Колмогорова [и др.]; под ред. проф. А.П. Сковородникова. Красноярск: Сиб. федер. ун-т, 2017. 340 с.

15. Панарин И.Н. СМИ, пропаганда и информационные войны. URL: https:/propagandahistory.ru/books/ (дата обращения: 11.01.2021).

16. Русинова М.П. Проблемы эффективной пропаганды ВФСК ГТО // Педагогическое образование в России. 2014. № 9. С. 87-89.

17. Сонин А.Г. Экспериментальное исследование поликодовых текстов: основные направления // Вопросы языкознания. 2005. № 6. С. 115-123.

18. Федотова М.Г. Пропаганда как технология информационной войны на Украине // Омские социально-гуманитарные чтения-2017. Материалы Х Международной научно-практической конференции. 2017. C. $155-159$. 
19. Экстремистский текст и деструктивная личность: монография / Антонова Ю.А., Веснина Л.Е., Ворошилова М.Б., Злоказов К.В., Тагильцева Ю.Р., Карапетян А.А. Екатеринбург: Урал. гос. пед. ун-т, 2014. $276 \mathrm{c}$.

20. Barron-Cedeno A., Jaradat I., Da San Martino G., Nakov. P. Proppy: Organizing the news based on their propagandistic content // Information Processing \& Management, vol.56 (5), 2019, pp. 1849-1864.

21. Iksoo Kwon. Conceptual mappings in political cartoons: A comparative study of the case of nuclear crises in US-North Korean relations // Journal of Pragmatics, 2019, vol. 143, pp. 10-27.

22. Jowett G., \& O’Donnell V. Propaganda and persuasion (6 $6^{\text {th }}$ ed.). Los Angeles, USA: SAGE, 2015. 481 p.

23. Lasswell H. (1927) The theory of political propaganda. American Political Science Review, vol. 21(3), 1927, pp. 627-631.

24. Marin-Arrese J.I. Political Cartoon Discourse: Creativity, Critique and Persuasion // Cultura lenguaje y representacion-revista de estudios culturales de la universitat Jaume I, 2019, vol. 22, pp. 117-134.

25. URL: https://www.usnews.com/cartoons/cartoons-on-north-korea (дата обращения: 15.12.2020).

\section{References}

1. Anisimova E.E. Lingvistika teksta i mezhkul turnaya kommunikaciya (na materiale kreolizovanny $x$ tekstov [Text linguistics and intercultural communication (based on creolized texts)]. Moscow: Akademiya Publ., 2003, 107 p.

2. Baranov A.N., Parshin P.B. Kategoriya propagandy` v lingvisticheskoj e'ks-pertize teksta [Category of propaganda in the linguistic review of the text]. Teoriya i praktika sudebnoj e 'kspertizy ' [Theory and practice of forensic examination], 2017, vol. 12, no. 2, pp. 53-65.

3. Bezborodova Yu.V., Korosteleva L.V. Kreolizovanny j tekst v strukture propagandistskogo diskursa [Creolized text in the structure of the discourse of propaganda]. Politicheskaya lingvistika [Political linguistics], 2019, no. 6 (78), pp. 159-163.

4. Belokoneva A.S. Konstruirovanie obraza vneshnego vraga: issledovanie sovetskih SMI i oficial'nyh dokumentov nachala holodnoj vojny [Con- 
structing the image of an external enemy: a study of the soviet media and official documents of the early cold war]. Abstract of $\mathrm{PhD}$ dissertation. Moscow, 2004, 24 p.

5. Vojtasik L. Ispol'zovanie psihologii v sisteme propagandy [The use of psychology in the propaganda system]. Reklama: vnushenie i manipulyaciya. Media-orientirovannyj podhod [Advertising: suggestion and manipulation. Media-oriented approach]. Samara: Bahrah-M Publ., 2001, $746 \mathrm{p}$.

6. Voroshilova M.B. Kreolizovannyj tekst v politicheskom diskurse [Creolized text within political discourse]. Politicheskaya lingvistika [Political linguistics], 2007, no. 3 (23), pp. 73-78.

7. Voroshilova M.B. Politicheskij kreolizovannyj tekst: klyuchi k prochteniyu: monografiya [Political creolized text: the keys to reading: the monograph]. Yekaterinburg: Ural State Pedagogical University Publ., 2013, $194 \mathrm{p}$.

8. Gudkov L.D. Negativnaya identichnost': stat'i 1997-2002 godov [Negative identity: articles from 1997 to 2002]. Moscow: Novoe lit. obozrenie Publ., 2004, 807 p.

9. Ejger G.V. K postroeniyu tipologii tekstov [On the construction of text tipology]. Lingvistika teksta: materialy nauch. konf. [Text linguistics: the proceedings of the scientific conference]. In 2 parts. Part 1. Moscow: MGPIIYA Publ., 1974, pp. 103-109.

10. Ivanov S.A. Propaganda i informacionnye vojny [Propaganda and information warfare]. Dnevnik altajskoj shkoly politicheskih issledovanij [Diary of the Altai school of political research], 2012, no. 28, pp.49-53.

11. Kameneva V.A. Manipulyaciya i/ili propaganda? Funkcional'nye osobennosti social'noj reklamy [Manipulation and/or propaganda? Functional features of social advertising]. Politicheskaya lingvistika [Political linguistics], 2013, no. 2 (44), pp. 35-39.

12. Kolmogorova A.V., Kalinin A.A., Taldykina Ju.A. Yazykovye markery manipulyacii v polyarizovannom politicheskom diskurse: opyt parametrizacii [Linguistic markers of manipulation in polarized discourse: parametric study]. Politicheskaya lingvistika [Political linguistics], 2016, no. 4 (58), pp. 194-199. 
13. Korduell M. Psihologiya. A-YA: Slovar'-spravochnik [Psychology. A-Z: Dictionary reference book]. Moscow: Fair-press, 2000, 448 p.

14. Lingvistika informacionno-psihologicheskoj vojny [Linguistics of information and psychological warfare]: monograph. Book 1. Krasnoyarsk: SFU Publ., 2017, 340 p.

15. Panarin I.N. SMI, propaganda i informacionnye vojny [The media, propaganda and information warfare]. URL: https://propagandahistory.ru/ books/ (accessed 11.01.2021).

16. Rusinova M.P. Problemy effektivnoj propagandy VFSK GTO [The problems of effective advocacy for All-Russian Sports Complex «Ready for Labor and Defense»]. Pedagogicheskoe obrazovanie v Rossii [Pedagogical education in Russia], 2014, no. 9, pp. 87-89.

17. Sonin A.G. Eksperimental'noe issledovanie polikodovyh tekstov: osnovnye napravleniya [An experimental study of polycode texts: the main areas]. Voprosy yazykoznaniya [Linguistic studies], 2005, no. 6, pp. 115-123.

18. Fedotova M.G. Propaganda kak tekhnologiya informacionnoj vojny na Ukraine [Propaganda as a technology of information warfare in Ukraine]. Omskie social'no-gumanitarnye chteniya-2017. Materialy X Mezhdunarodnoj nauchno-prakticheskoj konferencii [Omsk social and humanitarian readings-2017. Materials of the $\mathrm{X}^{\text {th }}$ international scientific and practical conference], 2017, pp. 155-159.

19. Ekstremistskij tekst $i$ destruktivnaya lichnost' [Extremist text and destructive personality]: monograph. Yekaterinburg: Ural. gos. ped. un-t Publ., 2014, 276 p.

20. Barron-Cedeno A., Jaradat I., Da San Martino G., Nakov. P. Proppy: Organizing the news based on their propagandistic content. Information Processing \& Management, vol. 56 (5), 2019, pp. 1849-1864.

21. Iksoo Kwon. Conceptual mappings in political cartoons: A comparative study of the case of nuclear crises in US-North Korean relations. Journal of Pragmatics, 2019, vol.143, pp. 10-27.

22. Jowett G., \& O’Donnell V. Propaganda and persuasion (6 ${ }^{\text {th }}$ ed.). Los Angeles, USA: SAGE, 2015, 481 p.

23. Lasswell H. The theory of political propaganda. American Political Science Review, vol. 21(3), 1927, pp. 627-631. 
24. Marin-Arrese J.I. Political Cartoon Discourse: Creativity, Critique and Persuasion. Cultura lenguaje y representacion-revista de estudios culturales de la universitat Jaume I, 2019, vol. 22, pp. 117-134.

25. URL: https://www.usnews.com/cartoons/cartoons-on-north-korea (accessed December 15, 2020).

\section{ДАННЫЕ ОБ АВТОРЕ}

Вагизова Виктория Викторовна, аспирант кафедры романских языков и прикладной лингвистики Института филологии и языковой коммуникации, старший преподаватель Военного учебного центра

Федеральное государственное автономное образовательное учреждение выстего образования «Сибирский федеральный университет»

пр. Свободный, 79, г. Красноярск, Красноярский край, 660041, Российская Федерациия

elka-vika@mail.ru

\section{DATA ABOUT THE AUTHOR}

Vagizova Viktoria V., post-graduate student of the Department of Romance Languages and Applied Linguistics, the School of Philology and Language Communication, Senior lecturer of the School of Military Training

Siberian Federal University

79, Svobodny pr., Krasnoyarsk, Krasnoyarsk region, 660041, Russian Federation

elka-vika@mail.ru 